\title{
Severity and Dimensions of Obsessive-Compulsive Disorder and Family Accommodation: OCD severity and Family Accommodation
}

\author{
Pragya Verma ${ }^{1}$, Pooja Mahour $^{2}$, P.K Dalal ${ }^{3}$, Vivek Agarwal ${ }^{4}$ \\ ${ }^{1}$ Child Psychologist, Department of Paediatrics, Integral institute of medical science and Research, Lucknow \\ ${ }^{2}$ Associate Professor, Department of Psychiatry KGMU, Lucknow U.P \\ ${ }^{3}$ Professor and Head of Department, King George Medical University, Lucknow, U.P \\ ${ }^{4}$ Professor, Department of Psychiatry KGMU, Lucknow U.P \\ Corresponding author: P.K. Dalal \\ Email-drpkdalal@rediffmail.com
}

\begin{abstract}
Background and Objectives: Family accommodation (FA) refers to ways in which family members assist the patient in the performance of rituals, compulsions, avoidance of anxiety provoking situations, or modification of daily routines to assist a relative with obsessive-compulsive disorder. The purpose of this study was to study the association between the family accommodation and dimensions of obsessivecompulsive disorder (OCD).

Methods: The study was included 45patients and their family members, Yale brown Obsessive-Compulsive scale (YBOCS) was used to assess the severity of OCD in patients and Dimensional Yale brown ObsessiveCompulsive scale (DYBOCS) was used to identify the severity of different dimensions in OCD patients family members were assessed on Family Accommodation Scale for Obsessive-Compulsive Disorder - Self Rated version (FAS-SR) for understanding accommodation level in family. A Pearson's correlation coefficient was used to evaluate the association between variables.

Results: FA was found to be highly present in the family of patients with OCD. On the DYBOCS we found the dimension of cleaning and washing were prevalent and highly correlated with FA.

Conclusion: The findings suggested that the family accommodation is very common in families of OCD patients and strongly associated with symptom severity of few specific dimensions.
\end{abstract}

Keywords: Family accommodation, obsessive-compulsive disorder, predictors, symptoms dimensions.

(Paper received $-9^{\text {th }}$ October 2018, Peer review completed $-28^{\text {th }}$ October 2018)

(Accepted $-4^{\text {th }}$ November 2018)

\section{INTRODUCTION}

Obsessive-Compulsive Disorder (OCD) is a heterogeneous disorder. According to the American Psychiatric Association, Obsessions present in the form of intrusive thoughts, images, or phrases that persistently enter into the individual's mind. Compulsions manifest by rituals or mental acts that need to be, repeatedly carried out, often in response to experiencing anxiety or distress due to an obsession. Affecting an estimated $1 \%$ of the adult population [1]. Individuals with OCD experience significant interference in various aspects of their lives including social, occupational, academic or family impairment [2]. Obsessive-compulsive disorder is an insidious condition that is capable of tricking and deceiving not only the sufferer, but his or her entire family as well. 
In the last few years family accommodation is a concept which has obtain specific interest in this area. Family accommodation can manifest in various forms including modifying family routines, engaging in the patient's compulsions, and facilitating avoidance of OCD triggers [3]. For instance, a parent or partner may engage in excessive hand washing rituals to assuage the patient's contamination fears, or excessively reassure the patient that the stove is turned off and the house will not burn down, Although family members often engage in these behaviours in hopes of attenuating OCD-related distress and mitigating the time occupied by symptoms [4]. OCD symptoms also allows the individual to avoid confronting his/her obsessional thoughts (through continued engagement in compulsions) and strengthens associations between these obsessions and anxiety. Thus, in the longer term, such family responses can also yield a negative impact, legitimizing patient's obsessional beliefs and creating an escalating cycle between family members' accommodating responses and OCD symptoms [5]. Approximately $75 \%$ of OCD relatives participated at least minimally in rituals or avoidance or modified their behaviour to accommodate patient's symptoms. Accommodation include providing reassurance $(>30 \%)$, active participation in rituals and/or avoidance at patient's request (33-60\%), taking over patient duties ( $>33 \%$ ), and modifying family activities and routines $(>35 \%)$ [4]. Higher levels of family accommodation are associated with increased OCD symptoms, increased functional impairment, and poorer therapeutic treatment outcome in both children and adults [4]. Symptom accommodation maintains the OCD symptomology by disallowing the individual with OCD to face their feared situations. The possible reason found by authors is that they suggest functional impairment in patients with OCD and long term adjustment with them OCD patient might influence the family function and family accommodation may be a work as a contributor in disturbed family functioning [3]. The aim of the study was to explore the severity of illness, dimensions of illness in OCD patients and level of family accommodation in patient's families and to determine possible associations between these variables.

\section{METHODOLOGY}

Purposive sampling method was used for sample selection. The study sample was drawn from Dept. of Psychiatry, King Georg's Medical University. Ethical committee of KGMU has approved this study, it was a cross-sectional study of Obsessive Compulsive Disorder patients and their family members. Written informed consent was taken from all patients and their family members in the study It included both old and newly registered patients diagnosed with Obsessive Compulsive disorder (as per DSM IV -TR) and the family members fulfilling the selection criteria were recruited in the study.

Operational definition of family member for the purpose of the study is taken from a previous study [6].

\section{Participants}

OCD patients and family members: We enrolled $(\mathrm{N}=45)$, patients Age between 18 to 60 years, Minimum education up to class Vth, Patients of OCD scored higher than 7 on YBOCS with and without comorbidity of Anxiety Disorders and Mood Disorder (Mild to moderate level of depression /anxiety), were not received any psychotherapeutic treatment (CBT and ERP) for OCD. Excludes patients with any other co-morbid psychiatric disorder, patients with a physical disability or condition requiring priority medical management and Use of substance except tobacco.

For each patient, we selected only one family members on the basis of the following criteria. Age between 18 to 60 years, living with the patient for at least 1 years, minimum education up to class $\mathrm{V}^{\text {th }}$, Not having received any psychotherapeutic treatment for distress related to their relationship with the OCD relative. We excluded the family members scored higher than 2 on GHQ-12 [7]. Presence of obsessive compulsive disorder in the family except patient. Family member with a physical disability or condition requiring priority medical management and use of other substance except tobacco.

The family members and patients were interviewed with the Structured Clinical Interview for DSM-IV TR Axis I Disorders, MINI [8] in order to exclude the presence of any current mental disorders.58 patients met criteria for one or more psychiatric disorders and therefore they were excluded from the study. 45 OCD patients with their healthy family members were finally included in the study. 


\section{Clinical Measures}

OCD patients and family members: A systematic face-to-face interview that consisted of structured and semi structured components was used to collect data from patients. All socio-demographic and illness characteristics were obtained through the administration of a semi structured interview covered with Sociodemographic data: age, sex, marital status and years of education. Mini International Neuropsychiatric Interview (M.I.N.I.) v.6.0.0 [8] was used to rule out comorbid psychiatric disorders in patients (except Anxiety and Depression). Obsessive-compulsive symptoms: OCD symptoms were measured with the YBOCS [9]; for assessing the overall severity and then applied DYBOCS [10] to assess the severity of multiple dimensions in the patients. Family accommodation was measured using the FAS-SR [11] a 19-item clinician-rated measure that assesses the degree to which family members of patients with OCD have accommodated patient rituals over the preceding month. In addition, the following rating scales were included in the assessment of OCD patients: Hamilton Rating Scale for Anxiety [12] and 17-item Hamilton Rating Scale for Depression [13].

\section{RESULTS}

Table-1 Descriptive statistics of the clinical Characteristics of patients with obsessive compulsive disorders.

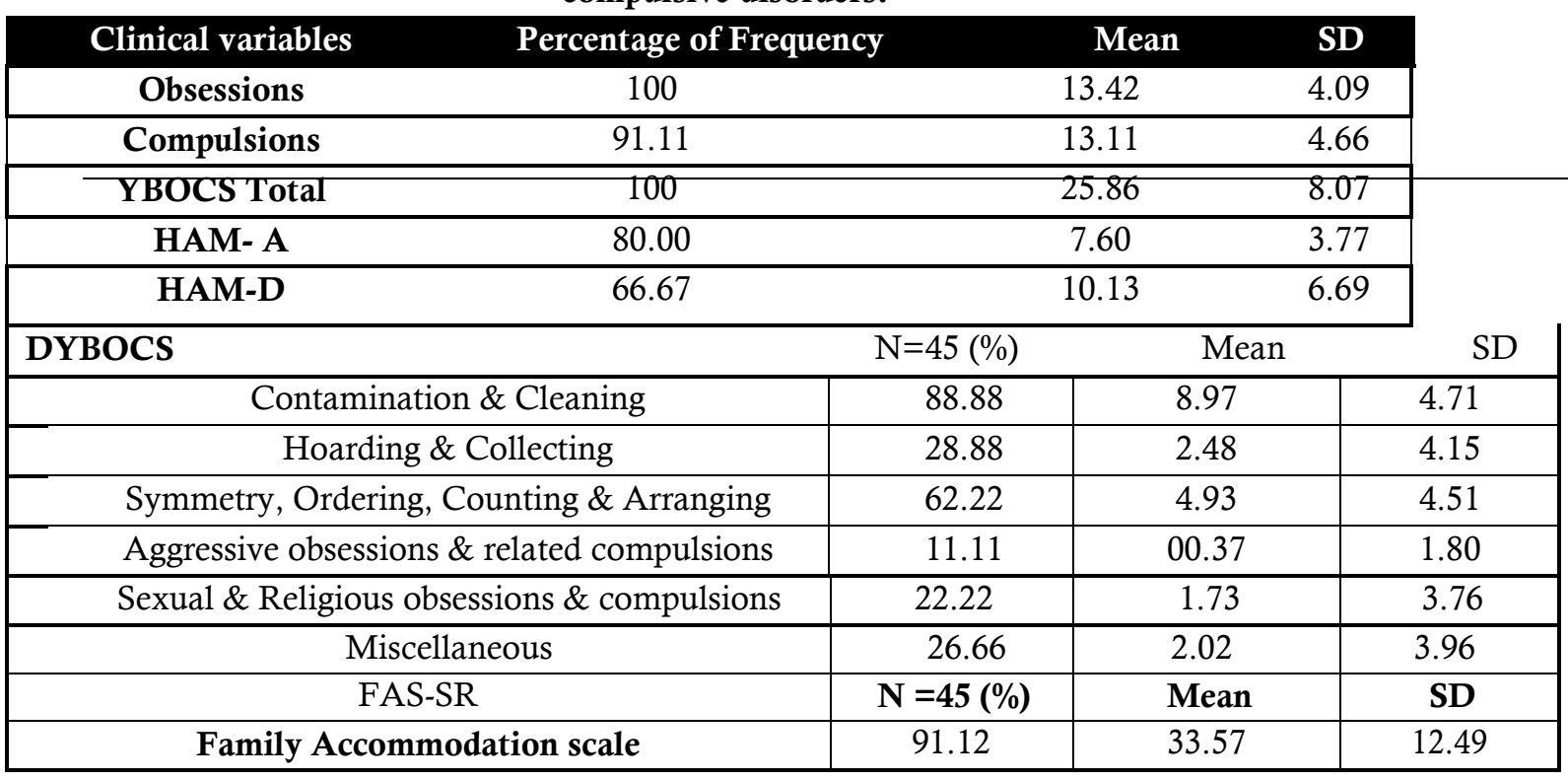

Mean score of Y-BOCS for obsession and compulsions were found 25.86 which indicates clinically significant severe level of OC symptoms. The mean scores (SD) on the FAS were $33.57 \pm 12.49$. Anxiety symptom was found present in around $80 \%$ patients and mean score of the HAM-A was 7.60 . Symptoms of depression was presented in 66\% patients mean score of HAM-D was found around 10.13. DYBOCS findings are suggestive that the indicative that around $89 \%$ patients were suffering with the dimension of cleaning and contamination and mean score of this dimension around 9. Second highly prevalent dimension in our sample was found Symmetry, Ordering, Counting \& Arranging

To explore the pattern of demographic variables in presented samples we entered current age, marital status, gender, family type and kinship with family. In which we find most of patient's age between the 1830 , females (57\%), married (53\%) and belongs to joint (67\%) family. We did not apply statistics on the clinical and demographic variables in the terms of examining the impact of OCD symptoms and comorbid. Age range of Patient's and family members was decided between 18 to 60 years. Mean score of patients age was found in the study sample was 30.60 years, Family member's age mean score was found 49 years. We observed the patients on the bases of their kinship and we found most of the family members referred by patients were spouses and parents (71\%). On the basis of kinship we found that most of the patients were came along with their husband (31.11\%) and father (35.55\%). Only $8.86 \%$ of family members were females. 
Table-2 Sociodemographic and clinical characteristics of the family members and patients with OCD $(\mathrm{N}=45)$

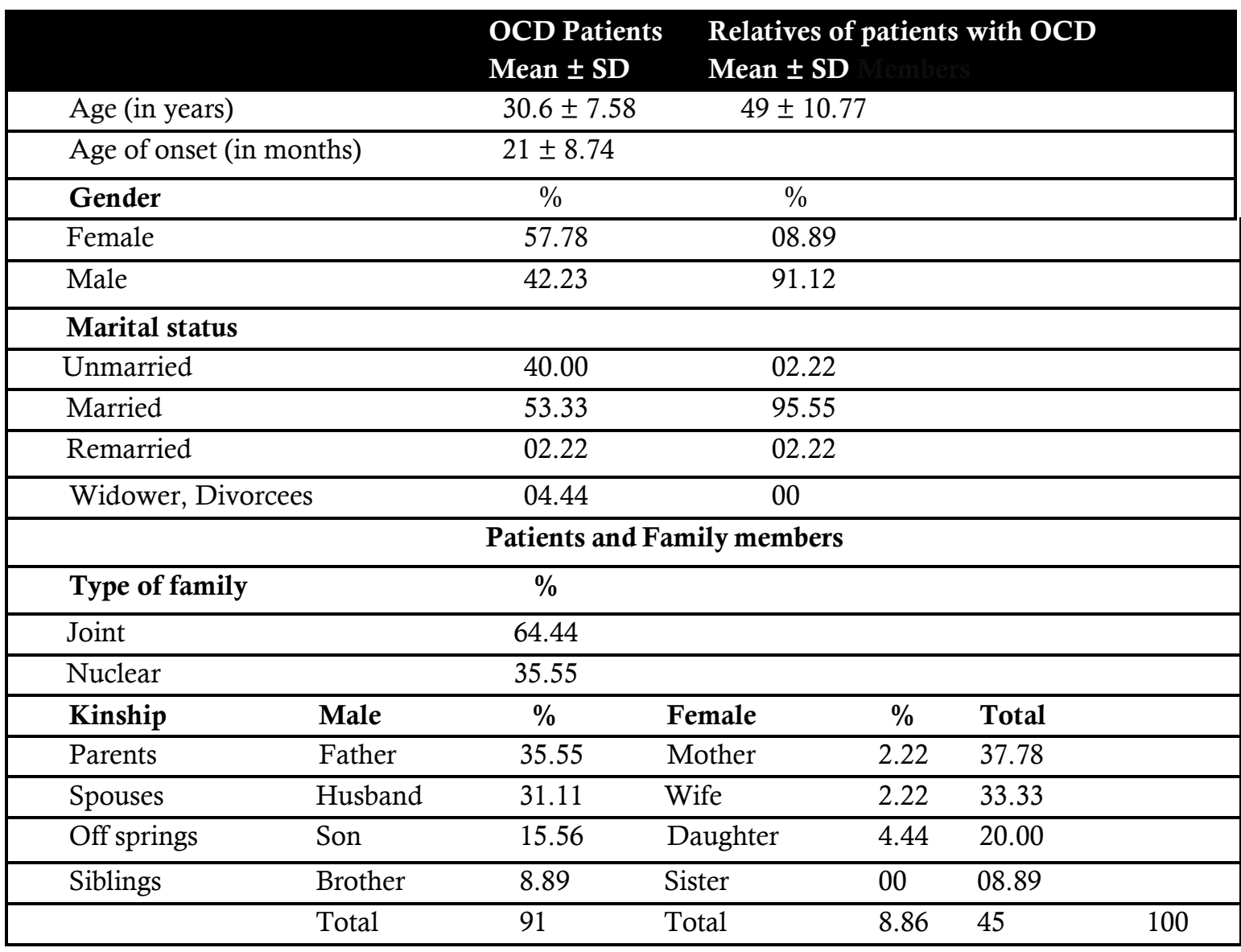

Table 3 presents there was a positive association between FAS scores and patient results for obsessions, compulsions, DYBOCS total scores. Family accommodation is positively correlated at significant level of 0.05 and 0.01 with YBOCS scores of obsessions (0.413), compulsion (0.607) and YBOCS total score (0.597) subscale of DYBOCS Contamination and cleaning (0.461), Symmetry, Ordering, Counting \& Arranging $(0.357)$ On the other hand last one subscale of Aggressive obsessions \& related compulsion $(-0.382)$ were found negatively correlated. Sexual and Religious (-0.075), and Miscellaneous (-0.240) were also found negatively correlated with FAS but not at the significant level.

Table 3 - Correlation between Family Accommodation and OCD

Family Accommodation Scale

\begin{tabular}{|ccc|}
\hline Variable & r value & p value \\
\hline Contamination \& Cleaning & 0.461 & $0.001^{*}$ \\
\hline Hoarding \& Collecting & 0.120 & 0.4320 \\
\hline Compulsions & 0.413 & $0.005^{*}$ \\
\hline Symmetry & 0.357 & $0.01^{*}$ \\
\hline Aggressive OCD & 0.382 & $0.01^{*}$ \\
\hline Sexual \& Religious obsessions & 0.075 & 0.622 \\
\hline Miscellaneous & 0.240 & 0.112 \\
\hline YBOCS Total & 0.597 & $0.006^{*}$ \\
\hline
\end{tabular}

*significant (Pearson's correlation used in the statistics) 


\section{DISCUSSION}

In this study, a sample of 45 adult patients with OCD and their family members was examined for the level of FA in family and its association with severity and dimensions of OCD, As expected, accommodating behaviours were highly prevalent among the family members studied: $97.45 \%$ stated that they provide accommodation to patients' OCD behaviours. The accommodating behaviours most frequently presented on a daily basis. These results are similar to those of previous studies [14-15] and, again, confirm that very often family members engage in some form of accommodation of OCD symptoms.

Family accommodation includes behaviours such as helping the patients by family member and feeling obliged to assist a patient with OCD, when he/she is performing a ritual or respecting the rigid rules that OCD imposes on the patient [16]. Family accommodation has been identified as a key maintaining factor of OCD [17-19]. OCD symptoms have a strong impact on the dynamics of family and caregivers [20].

In our study we found moderate correlation between severity of OCD and family accommodation, which suggests that as symptoms increase in severity, the family members are more likely to accommodate with the patients [21-22]. The dimensions of contamination \& cleaning, are found to be mildly correlated with family accommodation which indicates as the severity of the dimensions increases, the family members are more likely to accommodate with the patients. These finding are supported by other studies [23]. The dimensions of Symmetry, Ordering, Counting \&Arranging are found to be correlated but not at the significant level with family accommodation which indicates as the severity of the dimensions increases, the family members are more likely to accommodate with the patients [23].

As we found in the current study OCD-affected individuals often explicitly request or demand accommodation [3]. Therefore, it can be said that those symptoms which were explicit in nature as well as acceptable for family members, were found to be positively correlated with family accommodation [23]. Family accommodation inadvertently worsens OCD symptoms and is associated with increased disease severity, overall functioning impairment for the child or adult both [24].

In the current study a negative correlation is found between the dimension of Injury, violence, aggression, natural disaster related compulsions, aggressive obsessions \& related compulsions and sexual/religious obsessions with family accommodation, which indicates that as severity of the dimensions increases, the family members do not accommodate with the patients. These symptoms are implicit symptoms, unacceptable and as well as negative in nature therefore family members do not accommodate with patients. It can be a reason of less or no accommodation found with respect to these dimensions [23].

\section{CONCLUSION}

The present study replicated the high prevalence of FA among family members of OCD patients. The results of the correlation with family accommodation indicated that patient's OC symptom severity, as well as the presence of OC symptoms, such as washing or cleaning and symmetry, ordering and arranging in family members, increases the severity of illness or vice versa may possible.

Limitations and suggestions of the present study: The family members assessed were referred by patients, and may therefore have been the ones with the highest accommodation levels among all family members. Future research examining family factors associated with FA before and after the psychotherapeutic interventions are recommended.

\section{REFERENCES}

1. Subramaniam M, Soh P, Vaingankar JA, Picco L, Chong SA. Quality of life in obsessive-compulsive disorder: impact of the disorder and of treatment. CNS Drugs 2013;27(5):367-83.

2. Vikas A, Avasthi A, Sharan P. Psychosocial impact of obsessive-compulsive disorder on patients and their caregivers: a comparative study with depressive disorder. Int J Soc Psychiatry 2011;57(1):45-56.

3. Calvocoressi L, Lewis B, Harris M, Trufan SJ. Family accommodation in obsessive-compulsive disorder. Am J Psychiatry 1995;152(3):441-9.

4. Storch EA, Lewin AB, Geffken GR, Morgan JR, Murphy TK. The role of comorbid disruptive behavior in the clinical expression of pediatric obsessive-compulsive disorder. Behav Res Ther 2010;48(12):1204-10. 
5. Moulding R, Kyrios M. Anxiety disorders and control related beliefs: The exemplar of obsessive-compulsive disorder (OCD). Clin Psychol Rev 2006;26(5):573-83.

6. Gomes JB, Van Noppen B, Pato M, Braga DT, Meyer E, Bortoncello CF, Cordioli AV. Patient and family factors associated with family accommodation in obsessive-compulsive disorder. Psychiatr Clin Neurosci 2014;68(8):621-30.

7. Pevalin DJ. Multiple applications of the GHQ-12 in a general population sample: an investigation of longterm retest effects. Soc Psych Psychiatr Epidemiol 2000;35(11):508-12.

8. Sheehan DV, Lecrubier Y, Sheehan KH, Janavs J, Weiller E, Keskiner A, Schinka J, Knapp E, Sheehan MF, Dunbar GC. The validity of the Mini International Neuropsychiatric Interview (MINI) according to the SCID-P and its reliability. Eur Psychiatry 1997;12(5):232-41.

9. Moritz S, Meier B, Kloss M, Jacobsen D, Wein C, Fricke S, Hand I. Dimensional structure of the YaleBrown obsessive-compulsive scale (Y-BOCS). Psychiatr Res 2002;109(2):193-9.

10. Rosario-Campos MC, Miguel EC, Quatrano S, Chacon P, Ferrao Y, Findley D, Katsovich L, Scahill L, King RA, Woody SR, Tolin D. The Dimensional Yale-Brown Obsessive-Compulsive Scale (DY-BOCS): an instrument for assessing obsessive-compulsive symptom dimensions. Mol Psychiatry 2006;11(5):495-503.

11. Calvocoressi L, Mazure CM, Kasl SV, Skolnick J, Fisk D, Vegso SJ, Van Noppen BL, Price LH. Family accommodation of obsessive-compulsive symptoms: instrument development and assessment of family behavior. J Nerv Ment Dis 1999;187(10):636-42.

12. Maier W, Buller R, Philipp M, Heuser I. The Hamilton Anxiety Scale: reliability, validity and sensitivity to change in anxiety and depressive disorders. J Affect Disord 1988;14(1):61-8.

13. Williams JB. A structured interview guide for the Hamilton Depression Rating Scale. Arch Gen Psychiatry 1988;45(8):742-7.

14. Bogetto F, Venturello S, Albert U, Maina G, Ravizza L. Gender-related clinical differences in obsessivecompulsive disorder. Eur Psychiatry 1999;14(8):434-41.

15. Calvocoressi L, Libman D, Vegso SJ, McDougle CJ, Price LH. Global functioning of inpatients with obsessive-compulsive disorder, schizophrenia, and major depression. Psychiatr Serv 1998;49(3):379-81.

16. Cooper M. Obsessive- compulsive disorder: Effects on family members. Am J Orthopsychiatry 1996;66(2):296-304.

17. Barrett P, Shortt A, Healy L. Do parent and child behaviours differentiate families whose children have obsessive- compulsive disorder from other clinic and non- clinic families ?. J Child Psychol Psychiatry 2002;43(5):597-607.

18. Peris TS, Bergman RL, Langley A, Chang S, Mccracken JT, Piacentini J. Correlates of accommodation of pediatric obsessive-compulsive disorder: parent, child, and family characteristics. J Am Acad Child Adolesc Psychiatry 2008;47(10):1173-81.

19. Storch EA, Geffken GR, Merlo LJ, Jacob ML, Murphy TK, Goodman WK, Larson MJ, Fernandez M, Grabill K. Family accommodation in pediatric obsessive-compulsive disorder. J Clin Child Adolesc Psychol 2007;36(2):207-16.

20. Lebowitz ER, Panza KE, Su J, Bloch MH. Family accommodation in obsessive-compulsive disorder. Exp Rev Neurotherapeut 2012;12(2):229-38.

21. Lebowitz ER, Panza KE, Bloch MH. Family accommodation in obsessive-compulsive and anxiety disorders: a five-year update. Exp Rev Neurotherapeut 2016;16(1):45-53.

22. Amir N, Freshman M, Foa EB. Family distress and involvement in relatives of obsessive-compulsive disorder patients. J Anxiety Disord 2000;14(3):209-17.

23. Albert U, Baffa A, Maina G. Family accommodation in adult obsessive-compulsive disorder: clinical perspectives. Psychol Res Behav Manage 2017;10:293-9.

24. Derisley J, Libby S, Clark S, Reynolds S. Mental health, coping and family- functioning in parents of young people with obsessive- compulsive disorder and with anxiety disorders. Br J Clin Psychol 2005;44(3):43944.

$* * * * * * * * * * * * * * * * * * * * * * * * * * * * * * * * * * * *$

Acknowledgements - Nil

Conflict of Interest - Nil

Funding - Nil 